This document is confidential and is proprietary to the American Chemical Society and its authors. Do not copy or disclose without written permission. If you have received this item in error, notify the sender and delete all copies.

\title{
Redox-Triggered Buoyancy and Size Modulation of a Dynamic Covalent Gel
}

\begin{tabular}{|c|c|}
\hline Journal: & Chemistry of Materials \\
\hline Manuscript ID & $\mathrm{cm}-2019-00919 r . \mathrm{R} 2$ \\
\hline Manuscript Type: & Article \\
\hline $\begin{array}{r}\text { Date Submitted by the } \\
\text { Author: }\end{array}$ & 23-Apr-2019 \\
\hline Complete List of Authors: & $\begin{array}{l}\text { Das, Gobinda; New York University - Abu Dhabi, } \\
\text { Nagaraja, Sharadhi; Centre for Nano and Soft Matter Sciences } \\
\text { Sridurai, Vimala; Centre for Nano and Soft Matter Sciences, } \\
\text { Shinde, Digambar; King Abdullah University of Science and Technology, } \\
\text { PSE, AMPMC } \\
\text { Addicoat, Matthew; Universitat Leipzig, Wilhelm-Ostwald-Institut für } \\
\text { Physikalische und Theoretische Chemie } \\
\text { Prakasam, Thirumurugan; Center for science and Ingeneering, } \\
\text { Gándara, Felipe; Instituto de Ciencia de Materiales de Madrid, } \\
\text { Ravaux, Florent; Khalifa University of Science Technology - Abu Dhabi } \\
\text { Campus } \\
\text { Sharma, Sudhir Kumar ; New York University } \\
\text { Nair, Geetha; Centre for Nano and Soft Matter Sciences, } \\
\text { Lai, Zhiping; King Abdullah University of Science and Technology, } \\
\text { Division of Physical Science and Engineering } \\
\text { Jagannathan, Ramesh; New York University, NYUAD } \\
\text { Olson, Mark; Tianjin University, School of Pharmaceutical Science and } \\
\text { Technology } \\
\text { Trabolsi, Ali; New York University - Abu Dhabi, Chemistry }\end{array}$ \\
\hline
\end{tabular}

\section{SCHOLARONE ${ }^{\text {th }}$ Manuscripts}




\section{INTRODUCTION}

Soft actuators ${ }^{1-6}$ - materials that can reversibly change their shape in response to external stimuli such as small molecules, ${ }^{7}$ light,,${ }^{8,9}$ heat, or $\mathrm{pH}^{10,11}$ - are a fascinating class of responsive materials. ${ }^{12-14}$ Such materials are widely used in bio-medical treatment ${ }^{15}, 16$ and micromachine applications. $^{17-19}$ The most commonly studied molecular actuators are stimuli-responsive gels, ${ }^{13,20}$ supramolecular polymers, ${ }^{21-}$ ${ }^{23}$ host-guest complexes, ${ }^{24,25}$ and liquid-crystals. ${ }^{26}$ Such materials are capable of shape-morphing behaviors in response to external stimuli. ${ }^{911,19,21-25}$ The main drawback of supramolecular assemblies formed through non-covalent interactions is that they generally are not chemically resistant or thermally stable in solution. ${ }^{27,}{ }^{28}$ Covalent dynamic gels ${ }^{29-33}$ are another class of robust hybrid materials which can be constructed from a variety of functional organic building blocks via covalent assembly and are highly stable in many solvents. ${ }^{29,} 3^{0,33} \mathrm{~A}$ majority of the dynamic

gels reported in literature are obtained from uncharged neutral building blocks, ${ }^{29-33}$ whereas dynamic gels comprised of charged ionic building blocks are relatively unexplored. ${ }^{34}$ The incorporation of ionic scaffolds in covalent organic networks generates ionic interfaces that control the interactions with molecules and ions guests prompting the emergence of novel properties and functions distinct from those of the neutral skeletons. ${ }^{34,35}$ It can also be expected that introducing ionic moieties into conjugated covalent organic networks will contribute to the formation of increasingly stable ordered structures on account of their inherent electrostatic interactions. ${ }^{36-40}$ Moreover, the ability to exert control over the charge distribution of cationic structures for example, will allow for the modulation of electrostatic repulsions present in the scaffold as well as the extent of counterion condensation within the material, potentially inducing size and shape changes. ${ }^{3}$ Thusly, the 
design and synthesis of gel-based materials incorporating electroactive functional groups which respond mechanically to chemical and/or electrochemical stimuli ${ }^{41}$ remains a considerable challenge and an area of great interest for researchers., 42-44 Previously reported redox-responsive soft actuators are typically based on ferrocene-derived systems, ${ }^{41,} 45,{ }^{46}$ water soluble oligo-viologens, ${ }^{3}$ and polymer gels. ${ }^{41}$ However, covalent organic networks which function as an actuating system have yet to be reported. Recently, we introduced a number of viologen-based redox active polycationic covalent organic materials including gels obtained using the Zincke reaction. ${ }^{34,47,48}$ None of these materials displayed any shape deformation properties upon chemical reduction owing to the rigidity of their structures. We have now turned our attention to the rich redox chemistry of the flexible guanidinium-based ligands, ${ }^{49-51}$ capitalizing on the fact that they can be reversibly switched between a monocationic and a radical cation redox states through proton-coupled electron transfer mechanism (PCET). ${ }^{2-55}$ This switching process allows for the modulation of the hydration state of the gel material allowing for the release or the adsorption of water molecules from the network, leading to the shrinking or the swelling of the gel, respectively. ${ }^{56}$ We anticipated that the addition of a strong basic solution will deprotonate the guanidinium $-{ }^{+} \mathrm{N}-\mathrm{H}$ proton ( $\mathrm{pKa} \sim 12$ ) coupled to an electron transfer to form the radical cation $\mathrm{N}^{*+}$; a process that will control the actuation of our gel. Following through with this design strategy, we have prepared a guanidinium-based gel (noted TG-DFP, Figure 1a) obtained at room temperature from the imine condensation of a flexible triamino guanidinium hydrochloride salt $(\mathbf{T G} \cdot \mathrm{Cl})$ and diformyl pyridine (DFP). Unlike other neutral imine-based gels such as the one reported by Zhang et al. ${ }^{29}$ which exhibited a low tolerance to acids, our guanidinium-based gel was found to be exceptionally stable in $6 \mathrm{M} \mathrm{HCl}$ and $12 \mathrm{M} \mathrm{NaOH}$ for several days.

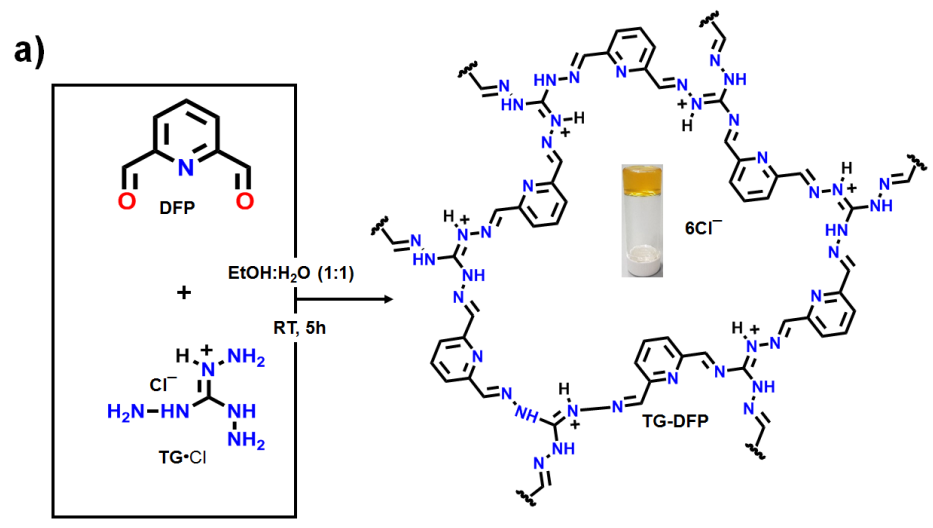

b)

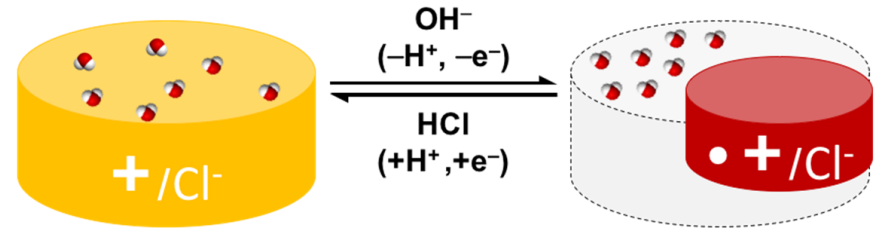

Figure 1: (a) Chemical structure and synthetic route of TG-DFP in water:ethanol (1:1, v:v) mixed solvent at room temperature. (b) Cartoon drawings showing the shrinking and swelling of the gel in response to base and acid: Addition of base $(\mathrm{NaOH}, 12 \mathrm{M})$ to an aqueous solution containing the gel, deprotonates the guanidinium unit (+) and oxidizes it to its radical cation $(\cdot+)$ form promoting the release of water molecules causing the gel to shrink with concomitant color change from yellow to red. The dashed counter in (b) represents the original size of the gel. Addition of $\mathrm{HCl}$ restores the cationic form of the gel, water molecules are re-adsorbed, and the gel regains its initial size and color. All experiments were performed in oxygen-rich solutions without any specific precautions taken.

The installation of a flexible guanidinium linker to the network provided significant electrostatic interactions and ion pair assisted $\mathrm{H}$-bonding around the imine bonds thus augmenting its material strength, the ability to gelate, and its chemical resistance. ${ }^{57}$ Interestingly, in the presence of base, the guanidinium moieties are oxidized to their guanidinyl radical cation state as proven by the appearance of a strong signal in the solid state electron paramagnetic resonance (EPR) spectrum of the base-treated gel. The formation of the radical cation occurs via a proton-coupled electron transfer (PCET) process. ${ }^{51}$ As anticipated, addition of $12 \mathrm{M} \mathrm{NaOH}$ solution deprotonated the ${ }^{+} \mathrm{N}-\mathrm{H}$ proton of the guanidinium unit and coupled to an electron transfer formed the $\mathrm{N}^{*+}$ state (Figure $\mathrm{bb}$ ). This oxidation process decreases the hydration state of the gel inducing a release of water molecules from the network as a result of the deprotonation of the guanidium unit which results in the contraction of the gel. The addition of $\mathrm{HCl}$ reprotonates the guanidinyl radical cations back to their cationic guanidinium form prompting the influx of water, causing expansion of the gel back to its original size.

\section{RESULTS AND DISCUSSION}

The synthesis of the gel network, TG-DFP, was achieved by mixing TG・Cl $(8.46 \mathrm{mg}$, $0.06 \mathrm{mmol})$ and DFP $(12.15 \mathrm{mg}$, $0.09 \mathrm{mmol})$ in $2 \mathrm{~mL}$ of a water:ethanol (1:1, v:v) mixed solvent at room temperature. A stable opaque gel formed 
within 4-5 hours which was confirmed by the inverted vial test (Figure 1a). The FT-IR spectrum (Figure S1) of the TGDFP wet gel showed the disappearance of the signal corresponding to the amine bond (-NH) at $\sim 3334 \mathrm{~cm}^{-1}$, the aldehyde $(-\mathrm{C}=\mathrm{O})$ groups at $1701 \mathrm{~cm}^{-1}$, and the appearance of a characteristically strong stretching band at around 1626 $\mathrm{cm}^{-1}$ which clearly indicate the consumption of the starting materials and formation of the imine bond, respectively.
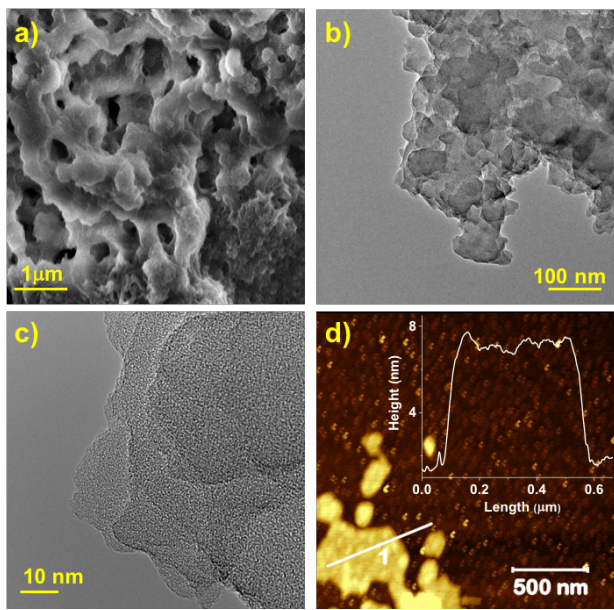

Figure 2: SEM (a), HR-TEM (b-c) and AFM (d) images of TG-DFP. The TG-DFP gel was first dispersed in ethanol and sonicated under ambient conditions for 1oh. A small volume of the ethanolic solution was then left to dry on a copper support before imaging. Microscopic characterizations show 2D-like nanosheets morphology.

Scanning, transmission electron, and atomic force microscopy (SEM, Figure 2a, HRTEM, Figures $2 \mathrm{~b}$ and $2 \mathrm{c}$, and AFM, Figure 2d) revealed that TG-DFP has a sheet-like morphology (Figures S2-S3). Using HR-TEM analysis at higher magnification (Figure 2c), stacked sheets were observed, which was further confirmed by AFM analysis. The atomic force microscopy image shown in figure $2 \mathrm{~d}$ was recorded to further evaluate the thickness of the TG-DFP nanosheets. The measured height was $\sim 5 \mathrm{~nm}$, denoting that the nanosheet was comprised of $\sim 15$ stacked layers, given that the $\pi-\pi$ stacking distance of the TG-DFP is $3.3 \AA$ obtained from powered X-ray diffraction (PXRD) analysis (Figure 3a).

The gel material exhibited weak broad PXRD peaks in the low angle region. The diffraction peak at $2 \theta=5.4^{\circ}$ can be assigned to the (100) plane of the regularly ordered lattice, and the broad peak at $2 \theta=26.67^{\circ}$ corresponds to the reflection from the (oo1) plane (Figure 3a) suggesting $\pi-\pi$ stacking. ${ }^{58}$ The atomic positions and cell parameters of TGDFP were optimized using the Self-Consistent-Charge Density-Functional Tight-Binding (SCC-DFTB) method as implemented in DFTB $+17.1 .{ }^{59}$ All atoms were described using the 3ob-3-1 parameter ${ }^{60,61}$ set and Lennard-Jones dispersion. In order to minimize the effect of the charged framework and "free" chloride ions, all optimizations used a $2 \times 2$ unit cell. Models based on distorted hcb layered structures (Figure $\mathrm{S}_{4}$ ) were generated in the trigonal $\mathrm{P}_{3}$ space group. Although the gel shows weak crystallinity and its conformation cannot be clearly distinguished between the eclipsed and the staggered, the best agreement between experimental and simulated PXRD patterns were obtained for eclipsed stacked structures with a triangular sequence (Figure $3 \mathrm{~b}$ ), resulting in unit cell parameters of a $=37.273, \mathrm{~b}=35.525 \AA$ and $\mathrm{c}=12.30 \AA$.

a)

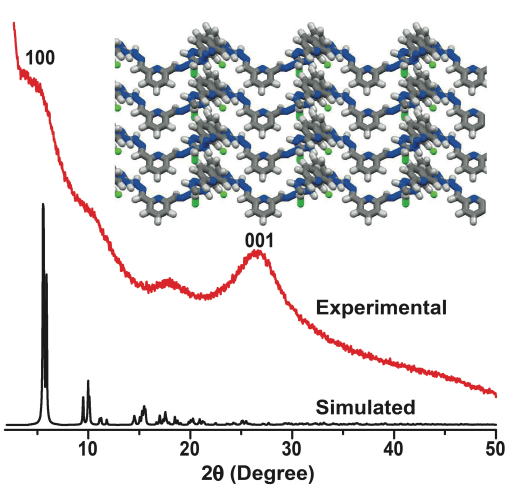

b)

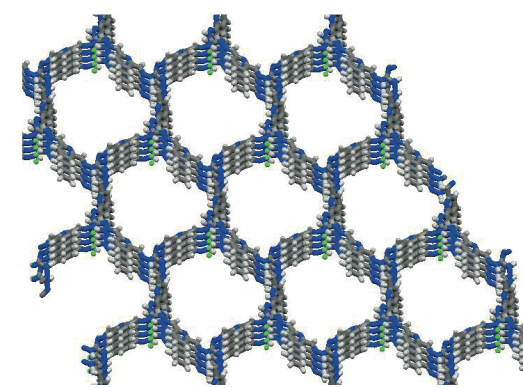

Figure 3: (a) PXRD pattern and simulated crystal structure of TG-DFP. Experimental PXRD pattern of the as-synthesized gel (red line), simulated XRD pattern using preferred eclipsed stacking (black line), and side view of a capped stick representation of four stacked layers of calculated TG-DFP (in-set); (b) Top view of a capped stick representation of stacked layers of the TG-DFP crystal structure. The simulated $2 \mathrm{D}$ unit cell parameters are $\mathrm{a}=37.273, \mathrm{~b}=$ $35.525 \AA$ and $\mathrm{c}=12.30 \AA$ A.

The structure is highly flexible compared to regular hcb layers due to the presence of the guanidinium moiety and the meta positions of the aldehyde groups in the pyridine linker, which imposes a non-linear connection between the triangular guanidine nodes. The broadness of the PXRD peak can be explained by the inherent flexibility of the guanidine linker connected in a $2 \mathrm{D}$-net. ${ }^{38}$ We note that though the X-ray pattern is quite broad, however there are some features in it which differentiate it from completely amorphous material. For example, there are three differentiated broad areas at $2 \theta$ below $20^{\circ}$, which suggest that there is a certain degree of long-range order periodicity, and that their positions are in agreement with a hexagonal layered structure. In addition, there is another clear broad peak centered at around $27^{\circ}$ that appears to be more intense than the peak corresponding to the 100 plane, which does not match the theoretical ratio of intensity in the simulated pattern. These observations could be attributed to the preferential orientation along the c-direction of TGDFP net, which is similar to those commonly found in layered materials (including graphite and carbon nitride). ${ }^{62}$ 
Taken together, these results suggest that the material can be described as having a certain degree of periodicity, and is not completely amorphous.

The permanent porosity of TG-DFP was assessed by $\mathrm{N}_{2}$ adsorption isotherms recorded at $77 \mathrm{~K}$, and exhibited a typeII adsorption isotherm, which is characteristic of mesoporous materials. The Brunauer-Emmett-Teller (BET) surface area was calculated to be $53 \mathrm{~m}^{2} \mathrm{~g}^{-1}$ (Figure $\mathrm{S}_{5}$ ). The relatively low surface area could be the related to the presence of the chloride counterions and the flexible nature of the structure. Low surface areas in cationic COFs were similarly reported earlier. ${ }^{34,38}$ Thermogravimetric (TGA) analysis under $\mathrm{N}_{2}$ atmosphere of TG-DFP revealed a thermal stability up to $200{ }^{\circ} \mathrm{C}$ (Figure S6).

Rheological studies were carried out to determine the mechanical properties of the gel network. A strain sweep experiment in which the oscillating strain $(\gamma)$ was varied from 0.001 to 5 at an angular frequency of $1 \mathrm{rad} / \mathrm{s}$ was conducted and the resultant stress was measured. The storage modulus $\left(G^{\prime}\right)$ and loss modulus $\left(G^{\prime \prime}\right)$ as a function of the applied strain are presented in figure $4 \mathrm{a}$. For TG-DFP, the viscoelastic moduli ( $G^{\prime}$ and $\left.G^{\prime \prime}\right)$ showed that $G^{\prime}>G^{\prime \prime}$ for low strain values, i.e., in the linear viscoelastic regime (LVR) TG-DFP clearly exhibited solid-like elastic behavior. ${ }^{34}$ Beyond the cross-over strain (denoted as $\gamma_{C}$ in figure $4 \mathrm{a}$ ), the material displayed liquid-like behavior, i.e., $G^{\prime \prime}>G^{\prime}$. For strain values corresponding to the regime beyond the LVR, both $\mathrm{G}^{\prime}$ and G" decreased, with G" giving rise to a weak strain overshoot (a 'peak-like' profile). This behavior is characteristic of soft glassy materials. The magnitude of the storage modulus $G^{\prime}$ (in the LVR) was found to be $\sim 100$ Pa whereas the cross-over strain at which the solid-like behavior becomes liquid-like is 1.3. Frequency sweep experiments were conducted in which the angular frequency $(\omega)$ was varied from 0.1 to $500 \mathrm{rad} / \mathrm{s}$ and the strain amplitude was fixed at 0.01 in order to be in the LVR. The resultant viscoelastic moduli, $G^{\prime}$ and $G^{\prime \prime}$ as a function of $\omega$ are shown in (Figure 4 b). The values of $G^{\prime}$ and $G^{\prime \prime}$ were independent of $\omega$ over a large frequency range indicating that the samples are true gels. In common with the values obtained from the strain sweep measurements, the $G^{\prime}$ value (in the frequency independent regime) is $\sim 100 \mathrm{~Pa}$. Beyond the critical value of $\omega$ (denoted as $\omega_{\mathrm{c}}$ in figure $4 \mathrm{~b}$ ), at $\sim 40 \mathrm{rad} / \mathrm{s}$, the gel broke down.
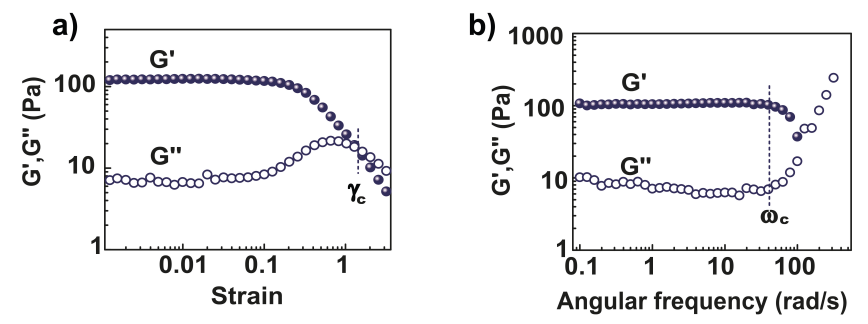

Figure 4. Rheological measurements of TG-DFP: (a) Strain sweep measurements and (b) Frequency-sweep measurements of the gel.

We also conducted steady state rheological studies in which continuous shear is applied to the sample while the bulk viscosity $(\eta)$ is measured as a function of shear rate $(\dot{\gamma})$. The share rate was varied over 5 orders of magnitude from $1 \mathrm{e}^{-2}$ to $1 \mathrm{e}^{2} \mathrm{~Hz}$ and the resultant shear rate dependence of the gel's viscosity is plotted in Figure S7a. TG-DFP exhibited a Newtonian plateau at low shear rates with viscosity values of $\sim 1500 \mathrm{~Pa} \bullet \mathrm{s}$. The plateau region extended up to a shear rate of $\sim 0.009$ to $\sim 0.004 \mathrm{~Hz}$. At higher shear rates, the viscosity of the gel sample decreased with increasing shear rate, a clear indicator of shear thinning, which is a characteristic feature of organogels. The plateau and thinning regimes are demarcated by dashed lines (Figure $\mathrm{S}_{7 \mathrm{a}}$ ). The shear rate dependence of viscosity in the thinning regime (Figure $S_{7 a}$ ) can be described by a power law, $\eta \propto \gamma^{\mathrm{n}-}$ ${ }^{1}$, where ' $n$ ' is the power law or flow index, which was found to be in the range $0.02-0.01$.

Guanidinium derivatives are very basic $\left(\mathrm{Pk}_{\mathrm{a}} \sim 12\right)$ and act as electron acceptors which allows them to undergo protoncoupled electron transfer (PCET) in the presence of electron donors such as $\mathrm{OH}^{-}$ions. ${ }^{51}$ We speculated that, the radical formation in the gel network would occur through PCET mechanism, ${ }^{63}$ by oxidation of the guanidinium $\left(-\mathrm{H}^{+}\right.$, $\left.-\mathrm{e}^{-}\right)$upon the addition of $\mathrm{NaOH}$, and reduction $\left(+\mathrm{H}^{+},+\mathrm{e}^{-}\right)$ after $\mathrm{HCl}$ addition. The formation of the radical was confirmed by solid state EPR studies (Figures $5 \mathrm{a}$ and $5 \mathrm{~b}$ ), whereby a sharp peak in the EPR spectrum was observed for the $\mathrm{NaOH}$-treated gel (10 $\mathrm{mL}, 12 \mathrm{M}$ ). The radical form of the gel was very stable as witnessed by the persistence of the EPR signal (Figure S8) recorded after seven days on the same base-treated gel. In order to confirm the PCET mechanism and get a better insight into the actuation process, we analyzed the chloride content of the gel before and after base addition (radical cation versus radical formation), by conducting energy-dispersive X-ray spectroscopy (EDX, Figure S9) measurements on the as-prepared cationic gel and the radical form. Interestingly, no net loss of chloride anions was observed before and after the addition of base. This observation rules out the single electron transfer mechanism which would be associated with a net loss of chloride anions as a consequence of the formation of a neutral radical species. The addition of base induces a noticeable color change of the gel from yellow to deep red as a result of radical formation. These results (EDX and EPR) coupled together confirm that the addition of $\mathrm{NaOH}$ induces a PCET mechanism. The oxidized radical cationic form of the gel can be reversibly reduced back to its cationic state by the addition of $\mathrm{HCl}$ (10 $\mathrm{mL}, 6 \mathrm{M})$. Reduction of the gel back to its cationic form was further confirmed by the absence of signal in the solid state EPR spectrum of the acid-treated gel.

Interestingly, the radical cationic form of the gel had a higher mechanical strength than the as-synthesized cationic form. Rheological studies revealed that the magnitude of the storage modulus $\mathrm{G}^{\prime}$ of the gel increased by a factor of 40 after $\mathrm{NaOH}$ treatment. The crossover strain was found to be $\gamma_{c}=0.3,4.3$ times lower compared to the $\gamma_{c}$ of the as-synthesised form (Figure $5 \mathrm{c}$ ). Frequency sweep experiments revealed that $\mathrm{G}^{\prime}$ of the oxidized form is $3800 \mathrm{~Pa}$, 38 times higher than $G^{\prime}$ of the reduced form. This behavior indicates that the oxidized radical cationic form of the gel is mechanically stronger than the as-synthesized cationic gel. The critical value $\omega_{\mathrm{C}}$ for the oxidized form of the gel was $80 \mathrm{rad} / \mathrm{s}$ (Figure $5 \mathrm{~d}$ ) and the shear rate was restricted 
to up to $\sim 0.004 \mathrm{~Hz}$. The flow index was found to be 0.01 . The flow index is a measure of the extent of shear thinning and it is clear from the values that the radical cationic form

a)

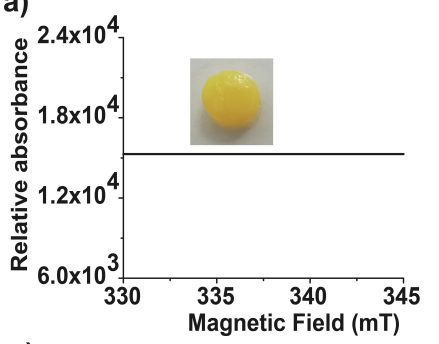

c)

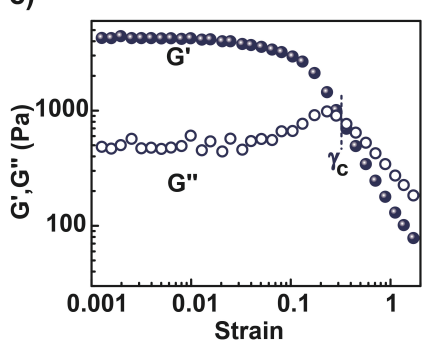

of the gel is more susceptible to shear thinning as compared to the as-synthesized cationic form (Figure S7b).

b)
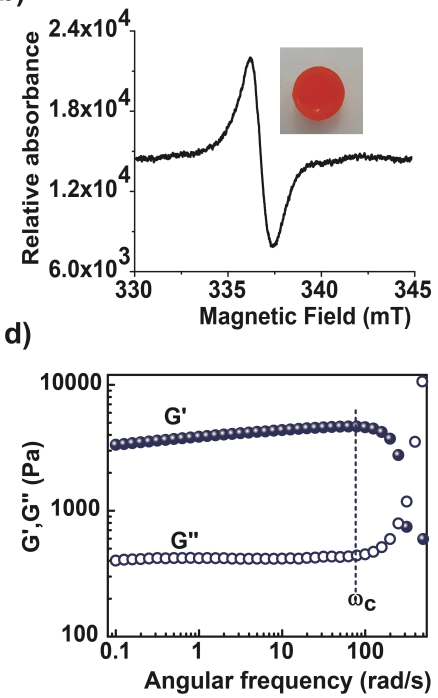

Figure 5: Solid state EPR spectra of the TG-DFP gel: as synthesized cationic form (a), and after $\mathrm{NaOH}(12 \mathrm{M})$ treatment (b), insets of (a) and (b) show digital photographs of the gel before and after exposure to a $12 \mathrm{M}$ solution of $\mathrm{NaOH}$ respectively; strain-sweep (c) and frequency sweep (d) measurements of the $\mathrm{NaOH}$-treated gel.

a)
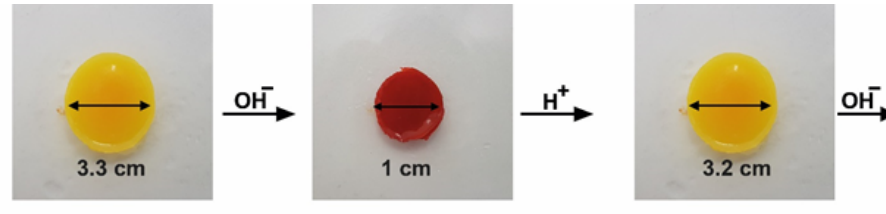

b)
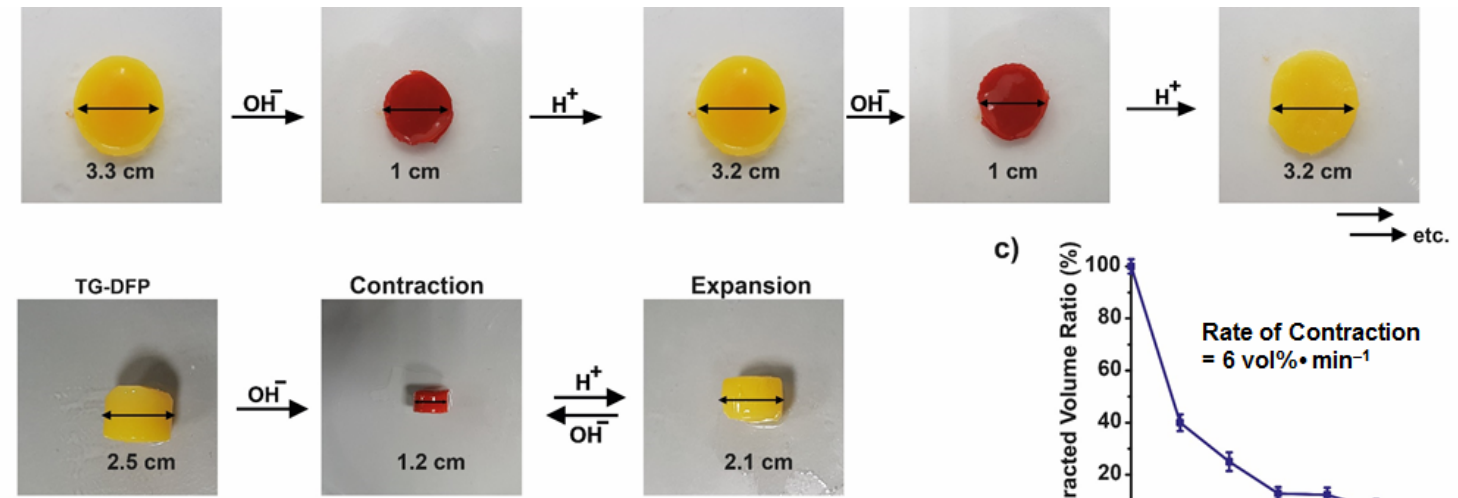

c)

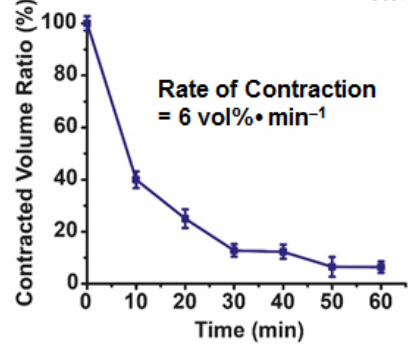

d)
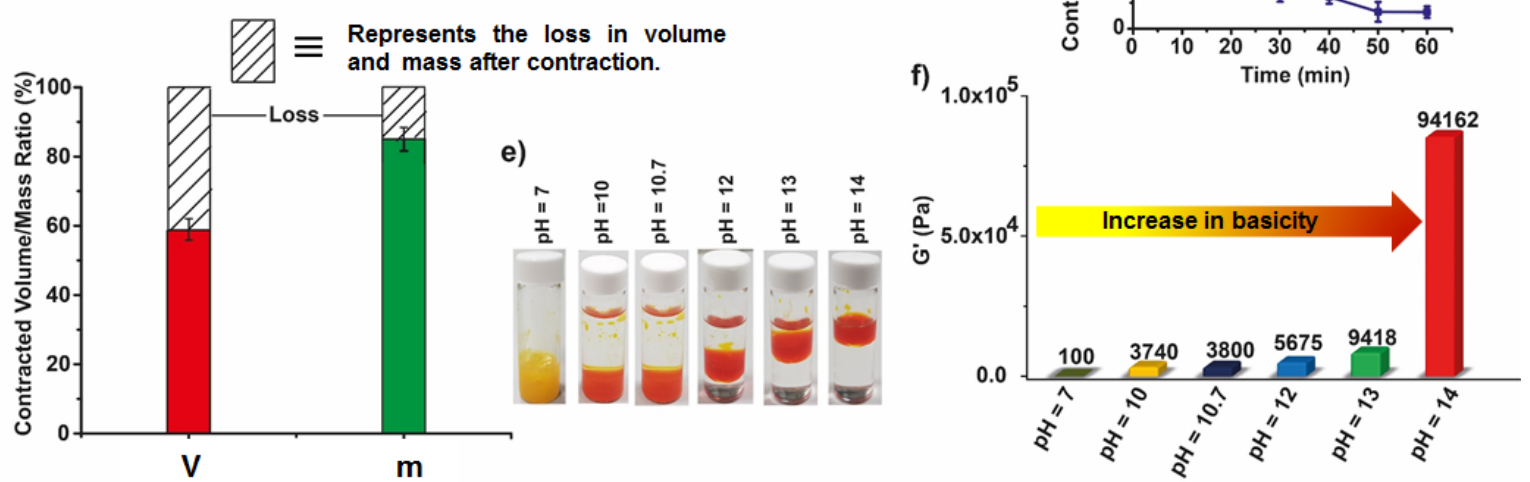

Figure 6: (a) Digital photographs showing the color change of TG-DFP gel from yellow (in acid) to red (in base) over four cycles; (b) Digital photographs showing the shape-morphing effect of base and acid on TG-DFP. The size of the gel shrinks upon addition of $\mathrm{NaOH}(12 \mathrm{M})$ and re-expands in presence of $\mathrm{HCl}$ acid $(6 \mathrm{M})$; (c) The contracted volume of the gel was calculated (in triplicate) for representing every $10 \mathrm{~min}$ in order to determine the rate of the actuation process, the rate was measured in the initial $10 \mathrm{~min}^{\text {1c }}$; (d) Bar graphs represent 60 min the volume/mass change of the TG-DFP gel, the observed values were measured in triplicate. The volume and mass of the gel after contraction are depicted in percentages $(\sim 60 \%$ and $85 \%$ of the original values respectively); (e) Photographs of TG-DFP showing the effect of base addition on the density of the gel. Increasing the basicity of the solution makes the gel less dense than water and the gel starts raising till it reaches the surface at $\mathrm{pH}=14$. (f) Effect of $\mathrm{pH}$ on the mechanical strength of TG-DFP gel showing a clear trend of increase of storage modulus $\mathrm{G}^{\prime}$ with the increase of $\mathrm{pH}$. 
The acid-base reversibility of the TG-DFP material was performed for 4 consecutive cycles (Figures 6a) without a noticeable degradation of the structure of the gel network. The expansion-contraction was regulated by using $\mathrm{NaOH}$ $(12 \mathrm{M})$ and $\mathrm{HCl}(6 \mathrm{M})$ solutions. A cylindrical piece of the as-synthesized yellow gel was immersed in $12 \mathrm{M} \mathrm{NaOH}$. Upon standing for 30 minutes, the gel material shrank in volume with a noticeable color change from yellow to red (Figure 6b). Following acid treatment, the gel re-expanded to its initial size over a period of $28 \mathrm{~h}$ and regained its initial color. To calculate the rate of contraction and the final volume/mass ratio, the gel was kept in the $\mathrm{NaOH}$ solution for one hour (Figure $6 \mathrm{c}$ ) and the percent ratio of volume and mass was measured (Figure 6d, Figures S10-Si1) at different time intervals. The degree of contraction in volume decreased with time till it reached a plateau after 1 hour. The contracted volume/mass ratio could be obtained (Figure $6 \mathrm{~d}$ ) as the percent ratio between the final volume/mass of TG-DFP after contraction to the volume/mass of the assynthesized gel. The rate of volume contraction (Figure 6c, figure S1o) of each of the disc-shaped gels was calculated in the first $10 \mathrm{~min}$, and was found to be $6 \mathrm{vol} \% / \mathrm{min}^{3}$

The addition of $\mathrm{HCl}$ induces the re-expansion of the gel material and leads to $\sim 99.7 \%$ regaining in mass after $28 \mathrm{~h}$ of treatment (Figure S11). The pyridine units of the network are susceptible to protonation upon addition of $\mathrm{HCl}$ acid. To confirm the protonation of pyridine moieties, we first synthesized the monomer ( $\mathrm{Scheme} \mathrm{S}_{1}$ ) from the condensation reaction between 2-pyridinecarboxaldehyde and triamino guanidine. ${ }^{1} \mathrm{H}-\mathrm{NMR}$ spectrum of the monomer showed a sharp singlet peak in the $\delta=9.36-8.90 \mathrm{ppm}$ region, which corresponds to the signals of the azomethine proton (Figure S12). When we treated the monomer with 6 $\mathrm{M} \mathrm{HCl}$, we observed a remarkable downfield chemical shift for both the signals of the azomethine and aromatic protons, which clearly indicated the formation of pyridinium ions. To gain further insight into the protonated form of the gel, X-ray photoelectron spectroscopy (XPS) analysis experiments were performed on the cationic as-synthesized TG-DFP and the HCl-treated TG-DFP. XPS measurements (Figure $\mathrm{S}_{13}$ ) on the as-synthesized gel showed a band at $398.5 \mathrm{eV}$ for the pyridinic $\left(-\mathrm{C}_{5} \mathrm{H}_{3} \mathrm{~N}\right)$ nitrogen atom corresponding to the $\mathrm{N}$ is peak which shifts to $401.2 \mathrm{eV}$ upon acid addition, which clearly confirmed the presence of pyridinium $\left(-\mathrm{C}_{5} \mathrm{H}_{3} \mathrm{NH}^{+}\right)$ions. EDX elemental analysis revealed that the percentage of chloride ions did not significantly differ between the pristine gel, figure Sga and its oxidized state upon base treatment (Figure Sgb). However, when the as-synthesized gel was treated with $6 \mathrm{M} \mathrm{HCl}$ acid, an increase in chloride ions was observed figure S9c which correlates with the protonation of pyridine units.

We also carried out a systematic investigation of the timedependent expansion and contraction of the gel in response to acid and base (Figure S14). Most of the contraction/expansion in shape occurs within the first $60 \mathrm{~min}$. A drastic change in the length of the gel could be observed during the oxidation process, so we also calculated the ratio of the length ( $r$ ) as a function of time (Figure S15), which was determined as $\mathrm{r}=\mathrm{L}_{2} / \mathrm{L}_{1} \times 100(\%)$ with $\mathrm{L}_{2}$ being the distance between two arbitrarily-selected points on the gel after oxidation and $\mathrm{L}_{1}$ the distance before oxidation. After the steep contraction, saturation was reached at $\mathrm{t}=6 \mathrm{o} \mathrm{min}$. The value of the length ratio was estimated to be $88.4 \pm$ $1.1 \%$ at time $t=5 \mathrm{~min}$, which finally reached $42 \pm 1.2 \%$ after $60 \mathrm{~min}$.

The observed contraction behavior may be attributed to the fact that during the oxidation process, TG-DFP loses a significant amount of water molecules. ${ }^{56}$ This in turn lowers the molecular weight of the material and the density of the gel network. The decrease in the density is clearly observed when a piece of the gel, initially in water at a $\mathrm{pH}$ of 7 , residing at the bottom of the beaker, is propelled to the surface when a solution of sodium hydroxide is added (Figure $6 \mathrm{c}$ ). A gradual elevation of the gel was observed depending on the $\mathrm{pH}$ of the solution till it reaches the surface at $\mathrm{pH}>12$. According to the experimental results shown in figure 6e, the gel material showed an instant color change color change and started to exhibit a buoyancy effect at $\mathrm{pH}$ $=12-14$.

The $\mathrm{pH}$-dependent strength of the gel was investigated using rheology. Figure $6 \mathrm{f}$ shows that the gel network is quite weak at $\mathrm{pH} \leq 10$. However, when the gel material is treated with a basic solution of $\mathrm{pH}$ values higher than 10, the gel exhibited a significant enhancement in strength. Frequency sweep tests were conducted for the gel material when treated at a $\mathrm{pH}$ range from 7 to 14 (Figure S16). At pH $=14$, the gel displatyed a storage modulus $G^{\prime}$ on the order of $\sim 10^{5} \mathrm{~Pa}$, which is extremely higher than previously published covalent organic gels. ${ }^{29,}{ }^{2,}, 34$ We also recorded the EPR spectra of the dry gel samples after treatment with aqueous solutions of different $\mathrm{pH}$ values. As it can be seen from figure $\mathrm{S}_{17}$, the intensity of EPR signal increases subsequently with the increase of basicity.

This actuation process could be repeated for 4 consecutive cycles with the structure of the TG-DFP gel remaining intact as confirmed by subsequent SEM, TEM, and PXRD analyses (Figures S18a-c). The retention of the macroscopic shape of the gel after many cycles suggests the possibility of non-covalent crosslinking between the observed $2 \mathrm{D}$ sheets. We hypothesize that water molecules bridge the sheets via hydrogen bonding. This hypothesis explains why the reversibility of the contraction-expansion process was observed with no loss of the macroscopic shape of the gel or sloughing off of layers.

To check the mechanical stability of the gel after five cycles of base/acid treatments, we carried out the frequency sweep experiment of the gel after the fourth cycle (Figure $\mathrm{S} 18 \mathrm{~d})$, at $1 \%$ strain amplitude, from 0.1 to $500 \mathrm{rad} / \mathrm{s}$. From frequency sweep experiments, it can be clearly seen that the elastic nature of the gel was retained and we were not able to see any crossover of $\mathrm{G}^{\prime}$ and $\mathrm{G}^{\prime \prime}$, even at higher frequencies. The storage moduli $G^{\prime}$ was greater than that of the loss moduli $\mathrm{G}^{\prime \prime}$. The magnitude of the storage modulus $\mathrm{G}^{\prime}$ in the linear viscoelastic regime (LVR) was found to be $\sim 221 \mathrm{~Pa}$, which clearly confirms the stability of the gel after several cycles of treatment with acid and base. However, 
the crystallinity of the network, after each cycle of contraction and expansion, decreases over time (Figure S19).

\section{CONCLUSION}

In summary, we have prepared a cationic imine-linked guanidinium-based dynamic gel that function as a redox responsive actuator by releasing or adsorbing water molecules depending on the redox state of the guanidinium units. The actuation behavior was triggered upon the addition of a concentrated solution of base which induces the deprotonation of the guanidinium units and coupled to an electron transfer process leads to the formation of the radical cation form of the gel which is of different color and contracted compared to the as-synthesized material. Addition of $\mathrm{HCl}$ acid restores the initial redox state of the guanidinium units and concomitantly the initial color and size of the gel. This actuation behavior is thought to be the consequence of the change in the hydration state of the gel upon deprotonation/oxidation or protonation/reduction. Water molecules are expelled upon the formation of the radical and re-adsorbed after protonation. The contraction-expansion process could be repeated for several cycles without any noticeable degradation of the material. Oxidation of the guanidinium units also permits the manipulation of the mechanical properties of the gel. The contracted gel is mechanically stronger and possesses enhanced elasticity. Moreover, this material can be easily accessed in a one-pot synthesis without the need for any additives to induce actuation. This design strategy can be adapted for the preparation of a wide range of new multifunctional materials with potential real-world applications.

\section{ASSOCIATED CONTENT}

\section{Supporting Information}

Synthetic procedures and TGA data of the synthesized materials; SEM, and TEM images of TG-DFP gel; porosity measurements, PXRD analysis, stability study and Rheology data.

\section{AUTHOR INFORMATION}

\section{Corresponding Author}

*ali.trabolsi@nyu.edu

\section{Author Contributions}

The manuscript was written through contributions of all authors.

\section{Funding Sources}

Any funds used to support the research of the manuscript should be placed here (per journal style). Notes The authors declare no competing financial interest.

\section{ACKNOWLEDGMENT}

The research described here was sponsored by New York University Abu Dhabi (NYUAD), UAE. G.D., T.P., S.S., R.J. and A.T. thank NYUAD for its generous support of the research program at NYUAD. The research was carried out by using the Core Technology Platform resources at NYUAD. MAA thanks the UK Materials Chemistry Consortium for HPC time on Thomas (EP/Po20194).

\section{REFERENCES}

1. Bar-Cohen, Y., Electroactive polymer (EAP) actuators as artificial muscles: reality, potential, and challenges. SPIE press Bellingham, WA: 2004; Vol. 5.

2. Madden, J. D.; Vandesteeg, N. A.; Anquetil, P. A.; Madden, P. G.; Takshi, A.; Pytel, R. Z.; Lafontaine, S. R.; Wieringa, P. A.; Hunter, I. W., Artificial muscle technology: physical principles and naval prospects. IEEE Journal of oceanic engineering 2004, 29, (3), 706-728. 3. Greene, A. F.; Danielson, M. K.; Delawder, A. O.; Liles, K. P.; Li, X.; Natraj, A.; Wellen, A.; Barnes, J. C., Redox-Responsive Artificial Molecular Muscles: Reversible Radical-Based Self-Assembly for Actuating Hydrogels. Chem. Mater. 2017, 29, (21), 9498-9508.

4.Liu, Y.; Flood, A. H.; Bonvallet, P. A.; Vignon, S. A.; Northrop, B. H.; Tseng, H.-R.; Jeppesen, J. O.; Huang, T. J.; Brough, B.; Baller, M.; Magonov, S.; Solares, S. D.; Goddard, W. A.; Ho, C.-M.; Stoddart, J. F., Linear Artificial Molecular Muscles. J. Am. Chem. Soc. 2005, 127, (27), 9745-9759.

5. Juluri, B. K.; Kumar, A. S.; Liu, Y.; Ye, T.; Yang, Y.-W.; Flood, A. H.; Fang, L.; Stoddart, J. F.; Weiss, P. S.; Huang, T. J., A Mechanical Actuator Driven Electrochemically by Artificial Molecular Muscles. ACS Nano 2009, 3, (2), 291-300.

6. Tian, Y.-H.; Kertesz, M., Molecular Actuators Designed with S: $\mathrm{N}(\mathrm{sp2})$ Hemibonds Attached to a Conformationally Flexible Pivot. Chem. Mater. 2009, 21, (10), 2149-2157.

7. Clark, P. G.; Day, M. W.; Grubbs, R. H., Switching and Extension of a [c2]Daisy-Chain Dimer Polymer. J. Am. Chem.Soc. 20o9, 131, (38), 13631-13633.

8.Mu, J.; Wang, G.; Yan, H.; Li, H.; Wang, X.; Gao, E.; Hou, C.; Pham, A. T. C.; Wu, L.; Zhang, Q.; Li, Y.; Xu, Z.; Guo, Y.; Reichmanis, E.; Wang, H.; Zhu, M., Molecular-channel driven actuator with considerations for multiple configurations and color switching. Nat. Commun. 2018, 9, (1), 590.

9. Tamesue, S.; Takashima, Y.; Yamaguchi, H.; Shinkai, S.; Harada, A., Photoswitchable supramolecular hydrogels formed by cyclodextrins and azobenzene polymers. Angew. Chem. Int. Ed. 2010, 49, (41), 74617464 .

10. Fang, L.; Hmadeh, M.; Wu, J.; Olson, M. A.; Spruell, J. M.; Trabolsi, A.; Yang, Y.-W.; Elhabiri, M.; Albrecht-Gary, A.-M.; Stoddart, J. F., Acid-Base Actuation of [c2]Daisy Chains. J. Am. Chem. Soc. 2009, 131, (20), 7126-7134.

11. He, L.; Fullenkamp, D. E.; Rivera, J. G.; Messersmith, P. B., pH responsive self-healing hydrogels formed by boronate-catechol complexation. Chem. Commun. 2o11, 47, (26), 7497-7499.

12. Yan, X.; Wang, F.; Zheng, B.; Huang, F., Stimuli-responsive supramolecular polymeric materials. Chemic. Soc. Rev. 2012, 41, (18), 6042-6065.

13. Wang, C.; Fadeev, M.; Vázquez-González, M.; Willner, I., StimuliResponsive Donor-Acceptor and DNA-Crosslinked Hydrogels: Application as Shape-Memory and Self-Healing Materials. Adv. Fun. Mater. 2018, 1803111.

14. Stuart, M. A. C.; Huck, W. T. S.; Genzer, J.; Müller, M.; Ober, C.; Stamm, M.; Sukhorukov, G. B.; Szleifer, I.; Tsukruk, V. V.; Urban, M.; Winnik, F.; Zauscher, S.; Luzinov, I.; Minko, S., Emerging applications of stimuli-responsive polymer materials. Nat. Mater. 2010, 9, 101. 15. Lu, Y.; Aimetti, A. A.; Langer, R.; Gu, Z., Bioresponsive materials. Nat. Rev. Mater. 2016, 2, 16075.

16. Lee, K. Y.; Mooney, D. J., Hydrogels for Tissue Engineering. Chem.Rev. 2001, 101, (7), 1869-1880.

17. Lutolf, M. P., Spotlight on hydrogels. Nat. Mater. 2009, 8, 451. 18.Kiyonaka, S.; Sada, K.; Yoshimura, I.; Shinkai, S.; Kato, N.; Hamachi, I., Semi-wet peptide/protein array using supramolecular hydrogel. Nat. Mater. 2003, 3, 58.

19. Roh, Y. H.; Ruiz, R. C. H.; Peng, S.; Lee, J. B.; Luo, D., Engineering DNA-based functional materials. Chem. Soc. Rev. 2011, 40, (12), 57305744 .

20. Vallejo-Sánchez, D.; Amo-Ochoa, P.; Beobide, G.; Castillo, O.; Fröba, M.; Hoffmann, F.; Luque, A.; Ocón, P.; Pérez-Yáñez, S., 
Chemically Resistant, Shapeable, and Conducting Metal-Organic Gels and Aerogels Built from Dithiooxamidato Ligand. Adv.Fun. Mater. 2017, 27, (15), 1605448.

21.Yamaguchi, H.; Kobayashi, Y.; Kobayashi, R.; Takashima, Y.; Hashidzume, A.; Harada, A., Photoswitchable gel assembly based on molecular recognition. Nat.Commun. 2012, 3, 603.

22. Kahn, J. S.; Hu, Y.; Willner, I., Stimuli-Responsive DNA-Based Hydrogels: From Basic Principles to Applications. Acc. Chem. Res. 2017, 50, (4), 680-69o.

23. Liu, J., Oligonucleotide-functionalized hydrogels as stimuli responsive materials and biosensors. Soft Matter 2011, 7, (15), 67576767.

24. Appel, E. A.; del Barrio, J.; Loh, X. J.; Scherman, O. A., Supramolecular polymeric hydrogels. Chem. Soc. Rev. 2012, 41, (18), 6195-6214.

25. Harada, A.; Takashima, Y.; Nakahata, M., Supramolecular Polymeric Materials via Cyclodextrin-Guest Interactions. Acc. Chem. Res. 2014, 47, (7), 2128-2140.

26. Kularatne, R. S.; Kim, H.; Boothby, J. M.; Ware, T. H., Liquid crystal elastomer actuators: Synthesis, alignment, and applications. J. Polym. Sci. Part B: Polym. Phys. 2017, 55, (5), 395-411.

27. Chang, J.; Zhao, Q.; Kang, L.; Li, H.; Xie, M.; Liao, X., Multiresponsive Supramolecular Gel Based on Pillararene-Containing Polymers. Macromolecules 2016, 49, (7), 2814-2820.

28. Kaufmann, L.; Kennedy, S. R.; Jones, C. D.; Steed, J. W., Cavitycontaining supramolecular gels as a crystallization tool for hydrophobic pharmaceuticals. Chem. Commun. 2o16, 52, (66), 1011310116.

29. Luo, W.; Zhu, Y.; Zhang, J.; He, J.; Chi, Z.; Miller, P. W.; Chen, L.; $\mathrm{Su}, \mathrm{C}$.-Y., A dynamic covalent imine gel as a luminescent sensor. Chem. Commun. 2014, 50, (80), 11942-11945.

3o. Zhang, J.; Liu, L.; Liu, H.; Lin, M.; Li, S.; Ouyang, G.; Chen, L.; Su, C.-Y., Highly porous aerogels based on imine chemistry: syntheses and sorption properties. J. Mater. Chem. A 2015, 3, (20), 10990-10998. 31. Zhong, H.; Fu, Z.; Taylor, J. M.; Xu, G.; Wang, R., Inorganic AcidImpregnated Covalent Organic Gels as High-Performance ProtonConductive Materials at Subzero Temperatures. Adv. Fun. Mater. 2017, 27, (32), 1701465.

32. Liao, P.; Hu, Y.; Liang, Z.; Zhang, J.; Yang, H.; He, L.-Q.; Tong, Y.X.; Liu, J.-M.; Chen, L.; Su, C.-Y., Porphyrin-based imine gels for enhanced visible-light photocatalytic hydrogen production. J. Mater. Chem. A 2018, 6, (7), 3195-3201.

33. Rabbani, M. G.; Sekizkardes, A. K.; Kahveci, Z.; Reich, T. E.; Ding, R.; El-Kaderi, H. M., A 2D Mesoporous Imine-Linked Covalent Organic Framework for High Pressure Gas Storage Applications. Chem. Eur. J. 2013, 19, (10), 3324-3328.

34. Das, G.; Skorjanc, T.; Sharma, S. K.; Gándara, F.; Lusi, M.; Shankar Rao, D. S.; Vimala, S.; Krishna Prasad, S.; Raya, J.; Han, D. S.; Jagannathan, R.; Olsen, J.-C.; Trabolsi, A., Viologen-Based Conjugated Covalent Organic Networks via Zincke Reaction. J.Am.Chem.Soc. 2017, 139, (28), 9558-9565.

35. Huang, N.; Wang, P.; Addicoat, M. A.; Heine, T.; Jiang, D., Ionic Covalent Organic Frameworks: Design of a Charged Interface Aligned on $1 \mathrm{D}$ Channel Walls and Its Unusual Electrostatic Functions. Angew. Chem.Int.Ed.2017, 56, (18), 4982-4986.

36. Chen, H.; Tu, H.; Hu, C.; Liu, Y.; Dong, D.; Sun, Y.; Dai, Y.; Wang, S.; Qian, H.; Lin, Z.; Chen, L., Cationic Covalent Organic Framework Nanosheets for Fast Li-Ion Conduction. J. Am. Chem. Soc. 2018, 140, (3), 896-899.

37. Zhang, W.; Zhang, L.; Zhao, H.; Li, B.; Ma, H., A two-dimensional cationic covalent organic framework membrane for selective molecular sieving. J. Mater. Chem A . 2018, 6, (27), 13331-13339.

38. Mitra, S.; Kandambeth, S.; Biswal, B. P.; Khayum M, A.; Choudhury, C. K.; Mehta, M.; Kaur, G.; Banerjee, S.; Prabhune, A.; Verma, S.; Roy, S.; Kharul, U. K.; Banerjee, R., Self-Exfoliated Guanidinium-Based Ionic Covalent Organic Nanosheets (iCONs). J. Am. Chem.Soc. 2016, 138, (8), 2823-2828.

39. Mal, A.; Mishra, R. K.; Praveen, V. K.; Khayum, M. A.; Banerjee, R.; Ajayaghosh, A., Supramolecular Reassembly of Self-Exfoliated Ionic Covalent Organic Nanosheets for Label-Free Detection of DoubleStranded DNA. Angew. Chem. 2o18, 57, (28), 8443-8447.
40. Du, Y.; Yang, H.; Whiteley, J. M.; Wan, S.; Jin, Y.; Lee, S. H.; Zhang, W., Ionic covalent organic frameworks with spiroborate linkage. Angew. Chem. Int. Ed. 2016, 55, (5), 1737-1741.

41.Wu, J.; Wang, L.; Yu, H.; Khan, R. U.; Haroon, M., Ferrocene-based redox-responsive polymer gels: Synthesis, structures and applications. J. Org. Chem. 2017, 828, 38-51.

42. Brochu, P.; Pei, Q., Advances in dielectric elastomers for actuators and artificial muscles. Macromol rapid commun. 2010, 31, (1), 10-36.

43. Fukino, T.; Yamagishi, H.; Aida, T., Redox-Responsive Molecular Systems and Materials. Adv. Mater. 2017, 29, (25), 1603888.

44. Guiseppi-Elie, A., Electroconductive hydrogels: synthesis, characterization and biomedical applications. Biomaterials 2010, 31, (10), 2701-2716.

45. Muraoka, T.; Kinbara, K.; Aida, T., Reversible operation of chiral molecular scissors by redox and UV light. Chem. Commun. 2007, (14), 1441-1443.

46. Iordache, A.; Oltean, M.; Milet, A.; Thomas, F.; Baptiste, B.; SaintAman, E.; Bucher, C., Redox Control of Rotary Motions in FerroceneBased Elemental Ball Bearings. J. Am. Chem. Soc. 2012, 134, (5), 26532671.

47. Das, G.; Prakasam, T.; Nuryyeva, S.; Han, D. S.; Abdel-Wahab, A.; Olsen, J.-C.; Polychronopoulou, K.; Platas-Iglesias, C.; Ravaux, F.; Jouiad, M.; Trabolsi, A., Multifunctional redox-tuned viologen-based covalent organic polymers. J. Mater. Chem. 2o16, 4, (40), 15361-15369. 48. Skorjanc, T.; Shetty, D.; Sharma, S. K.; Raya, J.; Traboulsi, H.; Han, D. S.; Lalla, J.; Newlon, R.; Jagannathan, R.; Kirmizialtin, S.; Olsen, J.C.; Trabolsi, A., Redox-Responsive Covalent Organic Nanosheets from Viologens and Calix[4]arene for Iodine and Toxic Dye Capture. Chem. Eur. J. 2018, 24, (34), 8648-8655.

49. Eberle, B.; Herrmann, H.; Kaifer, E.; Himmel, H. J., Redox Reactions Between Guanidine Electron Donors and Silver Dicyanamide: Synthesis of C, N Material Precursors and Coordination Polymers. Eur.J. Inorg. Chem. 2013, 2013, (21), 3671-3679.

50. Stang, S.; Lebkücher, A.; Walter, P.; Kaifer, E.; Himmel, H.-J., Redox-Active Guanidine Ligands with Pyridine and p-Benzoquinone Backbones. E. J. Inorg. Chem.2o12, 2012, (30), 4833-4845.

51. Wild, U.; Schön, F.; Himmel, H. J., Oxidation of Organic Molecules with a Redox-Active Guanidine Catalyst. Angew. Chem.Int. Ed. 2017, $56,(51), 16410-16413$.

52. Wild, U.; Hübner, O.; Greb, L.; Enders, M.; Kaifer, E.; Himmel, H.J., Twofold Oxidized and Twofold Protonated Redox-Active Guanidine: An Ultimate Intermediate in Proton-Coupled ElectronTransfer Reactions. Eur. J. Org. Chem. 2018, 2018, (43), 5910-5915.

53. Himmel, H.-J., Guanidines as Reagents in Proton-Coupled Electron-Transfer Reactions and Redox Catalysts. Synlett 2018, 29, (15), 1957-1977.

54. Hao, C.; Seymour, J. L.; Tureček, F., Electron Super-Rich Radicals in the Gas Phase. A Neutralization-Reionization Mass Spectrometric and ab Initio/RRKM Study of Diaminohydroxymethyl and Triaminomethyl Radicals. J. Phys. Chem. 2007, 111, (36), 8829-8843.

55. Hayakawa, S.; Matsubara, H.; Panja, S.; Hvelplund, P.; Nielsen, S. B.; Chen, X.; Tureček, F., Experimental Evidence for an Inverse Hydrogen Migration in Arginine Radicals. J. Am. Chem. Soc. 20o8, 130, (24), 7645-7654.

56. Zhang, F.; Fan, J.; Zhang, P.; Liu, M.; Meng, J.; Jiang, L.; Wang, S., A monolithic hydro/organo macro copolymer actuator synthesized via interfacial copolymerization. Npg Asia Mater. 2017, 9, e380.

57. Maity, A.; Gangopadhyay, M.; Basu, A.; Aute, S.; Babu, S. S.; Das, A., Counteranion Driven Homochiral Assembly of a Cationic $\mathrm{C}_{3-}$ Symmetric Gelator through Ion-Pair Assisted Hydrogen Bond. J. Am. Chem. Soc. 2016, 138, (35), 11113-11116.

58. Lukose, B.; Kuc, A.; Heine, T., The Structure of Layered CovalentOrganic Frameworks. Chem. Eur. J. 2011, 17, (8), 2388-2392.

59. Aradi, B.; Hourahine, B.; Frauenheim, T., DFTB+, a Sparse MatrixBased Implementation of the DFTB Method. J. Phys. Chem. A 2007, 111, (26), 5678-5684.

6o. Lu, X.; Gaus, M.; Elstner, M.; Cui, Q., Parametrization of $\mathrm{DFTB}_{3} / 3 \mathrm{OB}$ for Magnesium and Zinc for Chemical and Biological Applications. J.Phys.Chem. B 2015, 119, (3), 1062-1082.

61. Kubillus, M.; Kubař, T.; Gaus, M.; Řezáč, J.; Elstner, M., Parameterization of the DFTB3 Method for $\mathrm{Br}, \mathrm{Ca}, \mathrm{Cl}, \mathrm{F}, \mathrm{I}, \mathrm{K}$, and $\mathrm{Na}$ 
in Organic and Biological Systems. J.Chem. Theory Comput. 2015, 11, (1), 332-342.

62. Meng, Z.; Aykanat, A.; Mirica, K. A., Proton Conduction in 2D AzaFused Covalent Organic Frameworks. Chem. Mater. 2019, 31 (3), 819825 .
63. Gentry, E. C.; Knowles, R. R., Synthetic Applications of ProtonCoupled Electron Transfer. Acc. Chem. Res. 2016, 49, (8), 1546-1556. 
SYNOPSIS TOC

Insert Table of Contents artwork here

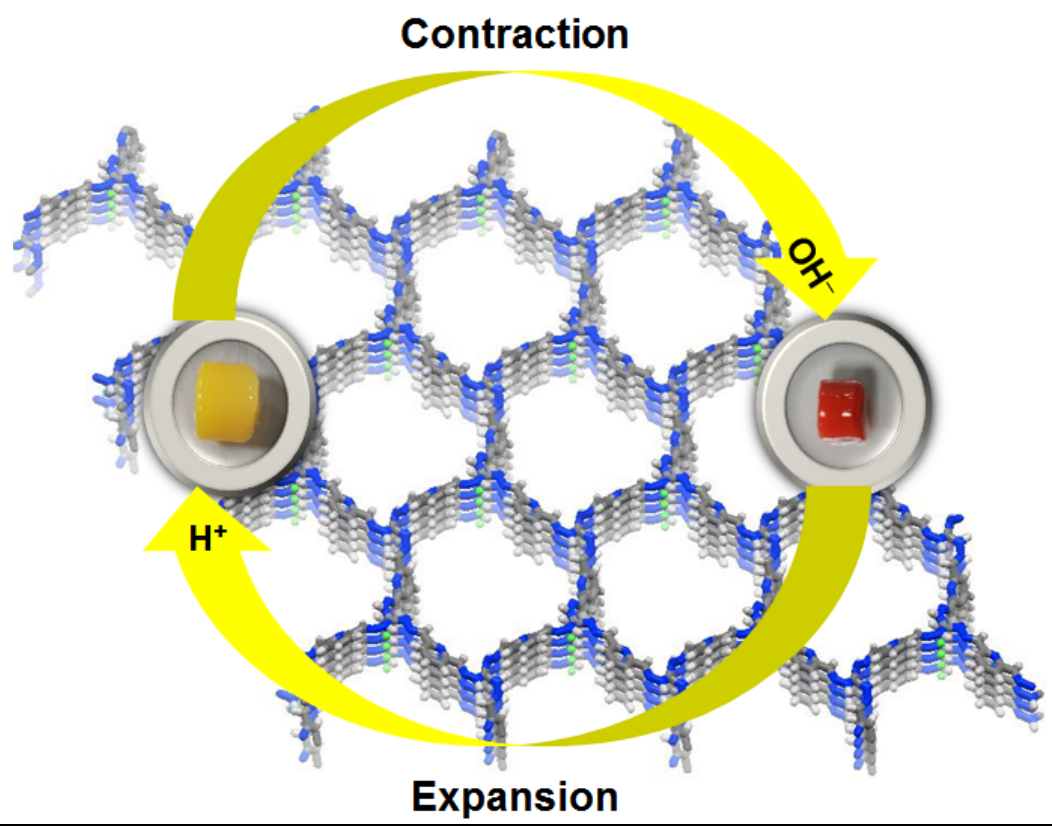

